\section{ScienceDirect}

Materials Today: Proceedings XX (2016) XXX-XXX materialstoday:
PROCEEDINGS

www.materialstoday.com/proceedings

\title{
ANM 2016 \\ Preparation and characterization of graphene oxide based membranes as possible Gas Diffusion Layers for PEM fuel cells with enhanced surface homogeneity
}

\author{
Alessandro Migliavacca*a, ${ }^{\text {a, }}$, Saverio Latorrata ${ }^{a}$, Paola Gallo Stampino ${ }^{\mathrm{a}}$ and Giovanni \\ Dotelli $^{\mathrm{a}}$ \\ a Dipartimento di Chimica, Materiali e Ingegneria Chimica "G. Natta”, Politecnico di Milano,p.zza Leonardo da Vinci 32, Milano 20133, Italia \\ ${ }^{b}$ Rold Research, Politecnico di Milano,p.zza Leonardo da Vinci 32, Milano 20133, Italia
}

\begin{abstract}
The aim of this work is to define and optimize a process to produce a membrane made of reduced graphene oxide, r-GO, aiming to use it as Gas Diffusion Layer, GDL, in a Polymer Electrolyte Membrane Fuel Cell, PEMFC. Some works have reported that $r$ GO could reach conductivity values of about $10^{4} \mathrm{~S} / \mathrm{m}$; by using the "self-assembling" properties of GO, it would be possible to obtain a GDL with enhanced homogeneity, which maintains a good electronic conductivity. A reduction process of GO in aqueous solution was developed in order to get the desired conductivity value of the final product. The membrane was characterized through several techniques to assess key parameters and to understand its properties. In this work it was possible to obtain a membrane which has a maximum contact angle of $86^{\circ}$ and a conductivity of about $421 \mathrm{~S} / \mathrm{m}$.
\end{abstract}

(C) 2016 Elsevier Ltd. All rights reserved.

Selection and Peer-review under responsibility of $7^{\text {th }}$ International Conference on Advanced Nanomaterials.

Keywords: Graphene oxide; Reduced graphene oxide; Characterization; Gas diffusion layer; PEM fuel cell; Ascorbic acid

\section{Introduction}

Fuel cells (FC) are electrochemical generators of energy that use a simple red-ox reaction between hydrogen and oxygen to produce electric current. They are promising devices for green-energy production: they have only water

* Corresponding author. Tel.: +39-02-2399-(3232) (9176).

E-mail address: alessandro.migliavacca@polimi.it 


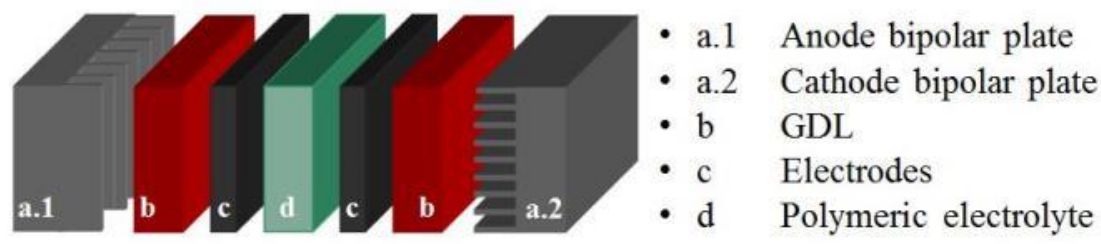

Fig. 1. Simplified representation of PEMFC components.

as by-product and use only one step to produce directly energy, instead of, for example, combustion engines. In particular, Proton Exchange Membrane Fuel Cells (PEMFCs) have been studied worldwide in order to have a continuous optimization of each component [1,2]. PEMFCs are composed of several components [Fig. 1], each of them has a particular function [1].

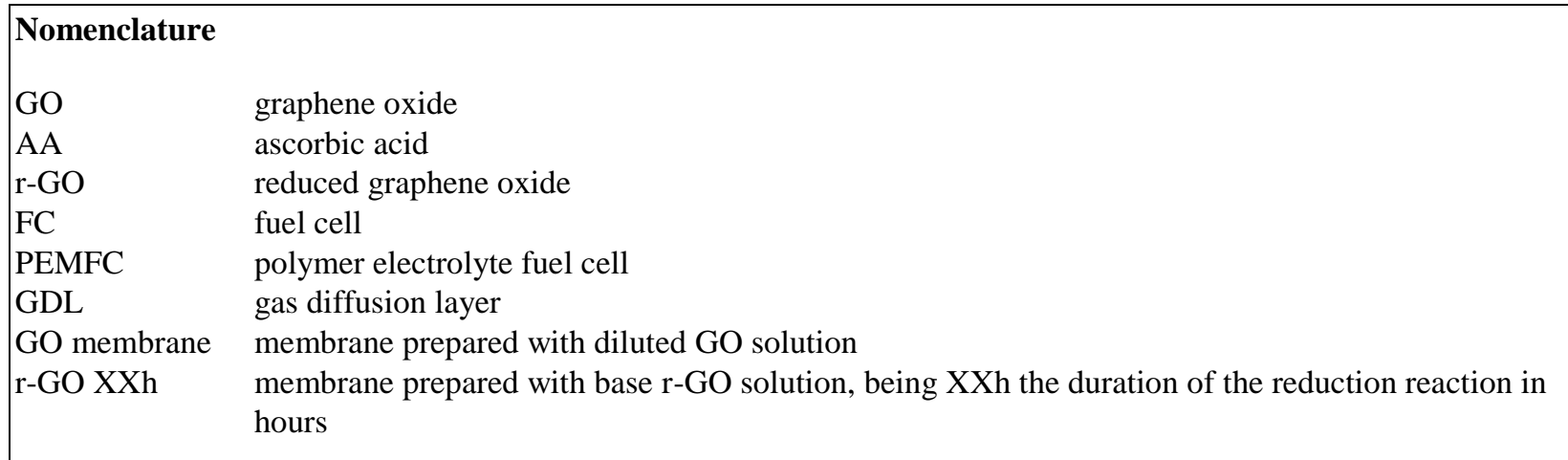

Gas Diffusion Layer (GDL) has different functions within the fuel cell, such as enabling the electronic conductivity, permitting the gas diffusion from the bipolar plates to the catalyst and managing the water of the whole cell [3]. In fact, GDL removes the exceeding water formed at the cathode, but at the same time, it permits a slight humidification of the membrane, that is mandatory to enhance the proton conduction. Through the analysis of these functions, it is possible to define main features of the materials which compose the GDL: they have to be porous, conductive and hydrophobic. GDL is usually made of two different layers, whose combination should impart these properties: one is a macro-porous layer, sometimes called back diffusion layer, and the second one is named micro-porous layer. Both are carbon-based, but to reach the desired hydrophobic properties a PTFE coating of the entire GDL is needed [4]. In this study the bases to create an entire "one piece" GDL are placed, in order to simplify the obtaining of the usual one. To do that a self-assembled material is selected. 


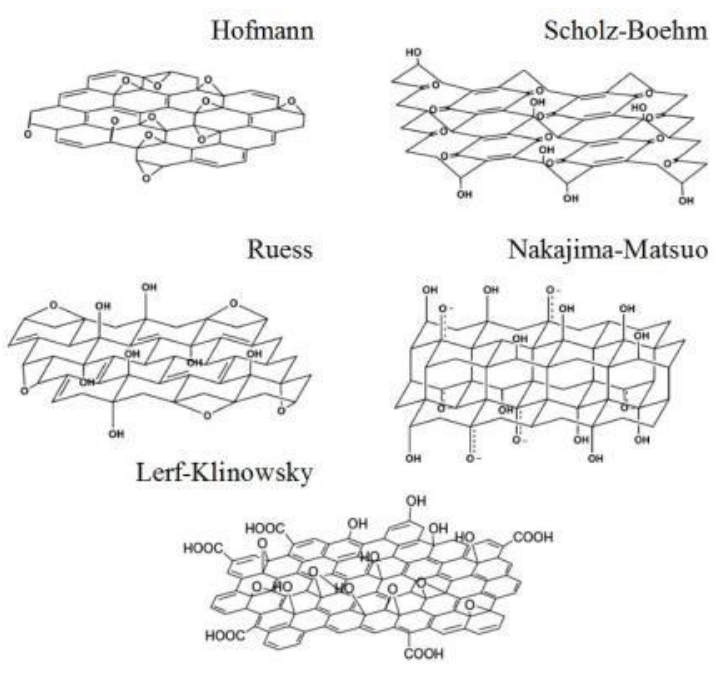

Fig. 2. Some proposed GO structures [5].

Graphene oxide has a bi-dimensional network similar to the one of graphene, in which some carbon atoms present $\mathrm{sp}^{3}$ hybridization, bonding to hydroxyl, carboxyl and epoxy groups [Fig. 2] [6]. It can easily form a selfassembling and self-standing membrane as widely described in literature, taking advantages from polar substituents present in its molecular structure [7-9]. In addition to self-assembling properties, GO is hydrophilic and shows insulator characteristics $[5,8,10]$, which, as mentioned before, are in contrast with main requirements of GDL materials. Therefore, it is mandatory to restore some original properties of graphene starting from the GO. This aim can be accomplished by reducing the graphene oxide, so eliminating some of its functional groups to reinstate the graphitic/graphene structure [11]. To reduce GO, several ways are possible, as described elsewhere [11, 12]. In this study a chemical reduction is proposed. The conventional process to chemically reduce GO employs hydrazine [13, 14], but it is well-known that it is a dangerous chemical which has to be manipulated with care, so it would be preferable moving on and searching for a different reducing agent. Analysing the literature [15, 16], it should be pointed out that a green chemical reduction is possible. The main problem of reduction is that the recovered graphene structure presents some defects that could negatively influence the conductivity properties needed by the desired material [17]. Thakur S. et al [15] have defined that the reduction by ascorbic acid (AA) has several advantages among all the reduction routes by naturally obtained reducing agents, such as, the obtainment of an aqueous dispersible r-GO and a good electrical conductivity of the reduced product. By using this reduction route, good values of conductivity could be reached: Fernández-Merino et al. obtained a maximum value of conductivity of about $7700 \mathrm{~S} / \mathrm{m}$, after the reaction of $2 \mathrm{mM}$ of AA with a $0.1 \mathrm{mg} / \mathrm{mL}$ of GO aqueous solution at $95{ }^{\circ} \mathrm{C}$ and demonstrated that the performances of reducing AA could be compared to those of hydrazine [12]. As widely demonstrated, the chemical reduction of GO can eliminate some groups on GO molecule $[12,15,18]$.

In this study GO reduction via AA has been performed, carefully monitoring the presence of polar groups that regulate self-assembling properties at different reaction times, with the aim of obtaining a r-GO based membrane characterized by both self-assembling properties, proper of GO, and hydrophobic and conductive properties, proper of graphene, needed for PEMFC application.

\section{Experimental}

\subsection{Reduction of $G O$ solution}

First of all, a colloidal solution of graphene oxide, purchased from Graphenea, with a concentration of $4 \mathrm{mg} / \mathrm{mL}$ was diluted to $25 \mathrm{~mL}$ with a final concentration of $0.25 \mathrm{mg} / \mathrm{mL}$. This solution was reduced with $62.5 \mathrm{mg}$ of AA, provided by Sigma Aldrich, by simply mixing AA powder with the GO solution at room temperature at $480 \mathrm{rpm}$ and 
for different reaction times: $12 \mathrm{~h}, 24 \mathrm{~h}, 36 \mathrm{~h}, 48 \mathrm{~h}, 72 \mathrm{~h}, 96 \mathrm{~h}$. This was done in order to have GO aqueous solutions at different reduction degrees. The weight ratio GO : AA is $1: 10$ [18]. Each of these solutions consisted in a base $r$ $G O$ solution for the membrane preparations described in the next paragraph.

\subsection{Production of the membranes}

To produce the membranes, each of the prepared base r-GO solution $(25 \mathrm{~mL})$ was filtered, by vacuum filtration, on a 0.22 Millipore membrane filter placed into a Buchner filter (diameter $4.8 \mathrm{~cm}$ ), as reported in literature [19-21] and schematized in Fig. 3. Membranes named $r$-GO XXh were obtained, where $X X$ represents the reduction time in hours $(12,24,36,48,72,96)$. Moreover, a membrane was obtained by the same procedure with a diluted GO, without any reduction; it represents the blank test solution and it is named GO Membrane [Fig. 4].

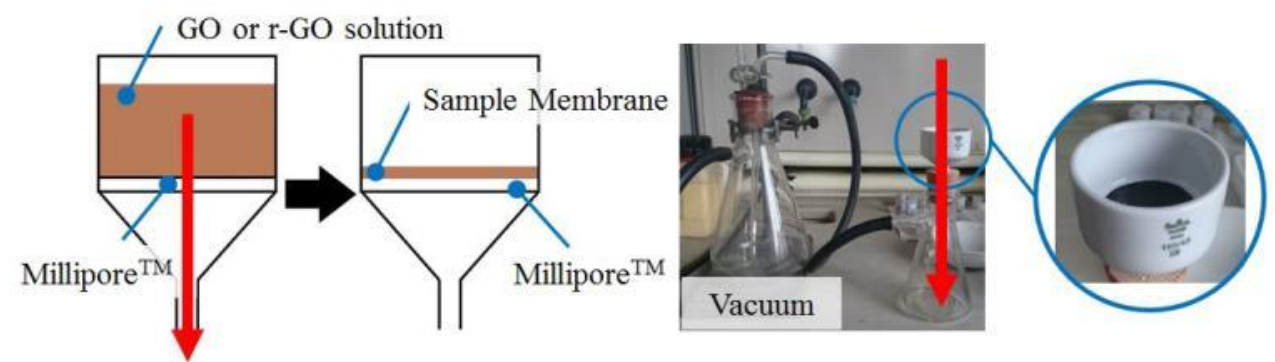

Fig. 3. Scheme of filtration set-up.
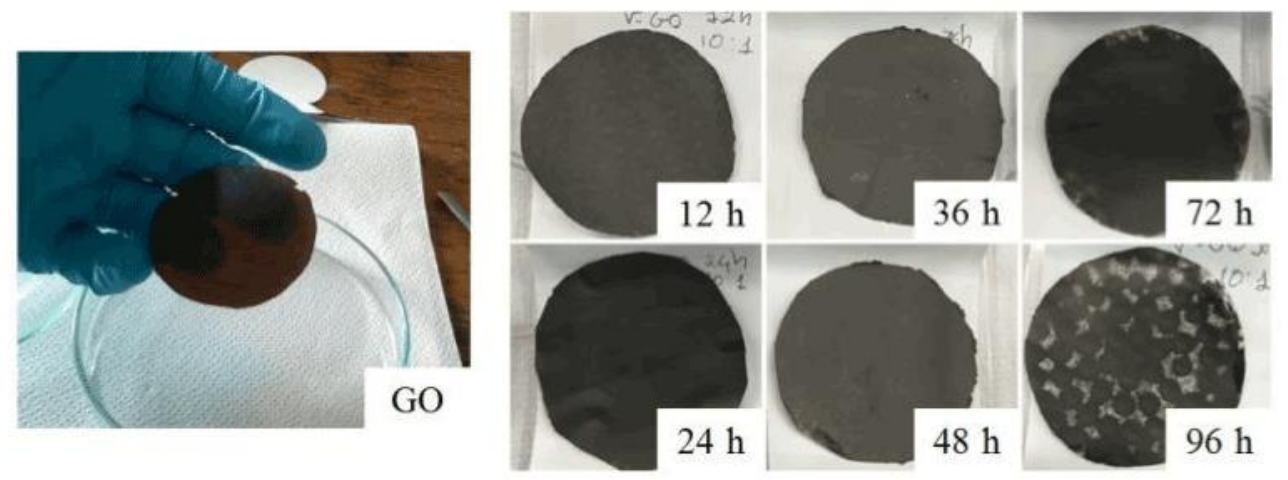

$72 \mathrm{~h}$
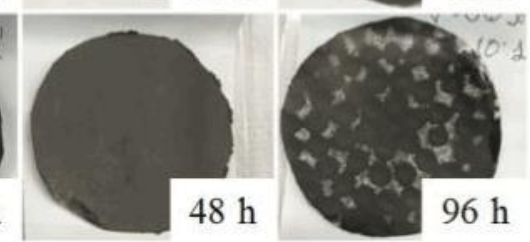

Fig. 4. GO and r-GO membranes obtained by filtration; it is possible to see that sample at $96 \mathrm{~h}$ does not present self-assembling properties.

\subsection{Characterization of the membranes}

The characterization of the obtained $\mathrm{r}$-GO and GO-based membranes is divided into three parts; each of them is devoted to evaluate different aspects of the products [Table 1]. 
Table 1. Characterization chart: $\bullet$ - test done; $\mathrm{x}$ - samples excluded from analysis.

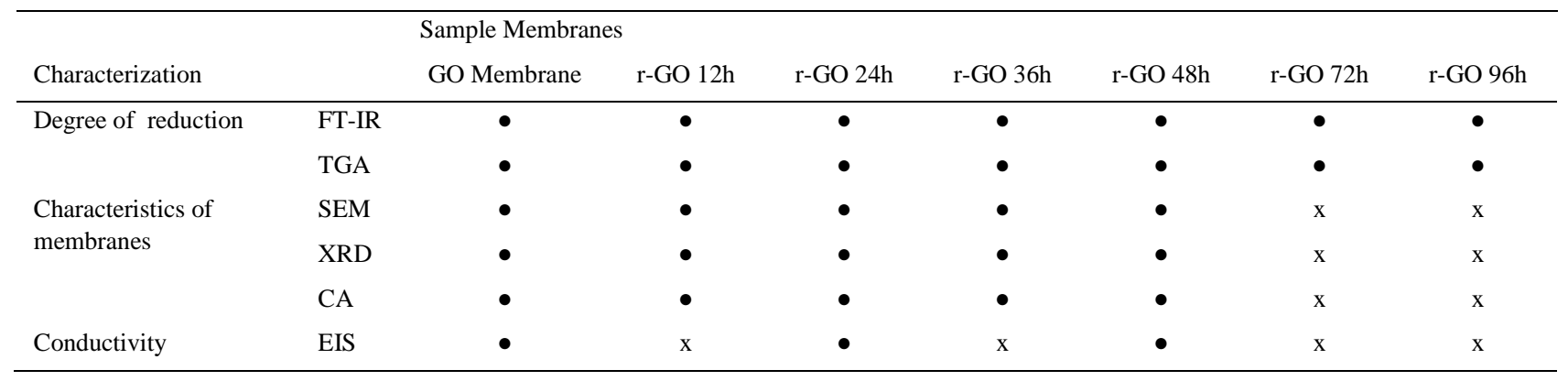

First of all the degree of reduction was explored by Fourier Transform Infrared (FT-IR) spectroscopy and Thermo-gravimetric analysis (TGA), trying to analyze the effect of the reduction on the base solution. The former was performed by Jasco FT/IR - 615 in 4000-400 $\mathrm{cm}^{-1}$, while the latter by TG/DTA 6300 EXTAR 6000 SII Seiko Instruments, on nitrogen, with a linear temperature ramp of $5{ }^{\circ} \mathrm{C} / \mathrm{min}$ from $25^{\circ} \mathrm{C}$ to $1000^{\circ} \mathrm{C}[13,22]$.

Structure and morphology of the membranes were analyzed by Scanning Electron Microscopy (SEM) and X-ray Diffraction (XRD) and the hydrophobic properties were assessed by means of contact angle (CA) measurements. SEM was used to establish regularity of membranes' surfaces and to assess thickness of the samples; it was performed by Zeiss EVO $50 \mathrm{EP}$ scanning electron microscope. X-ray diffraction was done by instrument BRUKER $\mathrm{D} 8$, with a Cu radiation source which has a wavelength of $1.541 \AA$, with a scansion step size of $0.02^{\circ}$, from $2^{\circ}$ to $30^{\circ}$ $\theta$ degrees and a count time of $1 \mathrm{~s}$. In XRD measurements Millipore membrane, deriving from production process, was used as substrate of the sample membranes. Contact angle measurements were executed by Dataphysics OCA 20 and for each sample membrane at least 10 measurements were valued.

As final step, conductivities of the membranes were calculated, by impedance spectroscopy (EIS), performed by a Solartron Analytical 1260, whose electrodes were connected to the handmade system presented in Fig. 5. The samples were cut into a flap with the dimensions reported in Fig. 5. After the application of a sinusoidal voltage input with a variable frequency, impedance $Z$ was measured. Nyquist diagrams, whose typical example is presented in Fig. 6, were collected and elaborated using Zview ${ }^{\circledR}$ (Scribner Associates) software. This graph has the real part of the impedance Z' as X-axis, while the imaginary one Z' ' as y-axis. It is possible to connect the real part Z' to the resistance produced by the tested material. A signal of amplitude $500 \mathrm{mV}$ and a frequency range from $0.5 \mathrm{~Hz}$ to $10^{6}$ $\mathrm{Hz}$ were used.

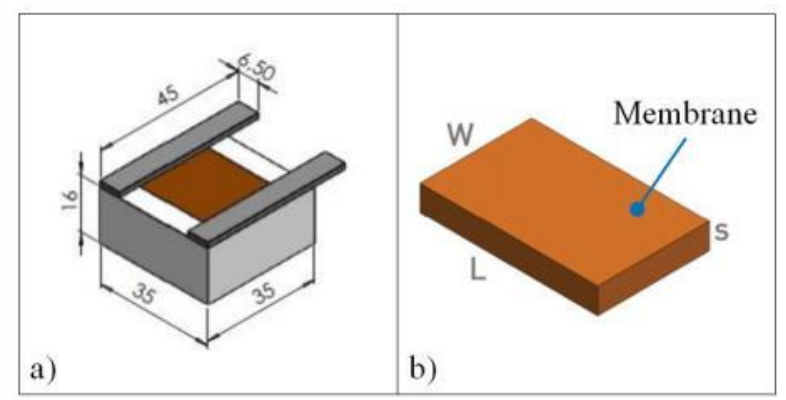

Fig. 5. Impendence set-up: a) handmade system, with dimensions in [mm]; b) membrane cut flap, where $\mathrm{W}=2.2 \mathrm{~cm} \mathrm{~L}=3.5 \mathrm{~cm} \mathrm{~s}=1.5 \mu \mathrm{m}$. 


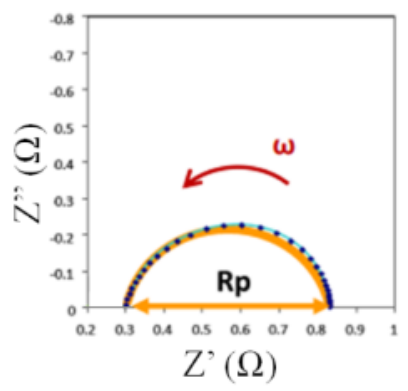

Fig. 6. Typical Nyquist diagram, $\omega=$ angular frequency; Rp is the membrane resistance R.

\subsubsection{Calculation of conductivity}

As mentioned, membrane resistance $\mathrm{R}$ is calculated as the difference between the intercepts of the impedance spectrum on the $\mathrm{x}$-axis of the Nyquist diagram. Then, resistivity of the membrane is obtained by the Ohm equation (1):

$$
\rho=R \cdot \frac{L \cdot S}{W}
$$

Where $\rho=$ resistivity $[\Omega \cdot m], R=$ Resistance connect to Z' value, extrapolated from Nyquist Diagram $[\Omega], L=$ linear distance between electrodes $[\mathrm{m}], \mathrm{W}=$ width of membrane $[\mathrm{m}]$ and $\mathrm{s}=$ thickness of membrane, estimated from SEM analysis [m]. In particular: $\mathrm{L}=0.022 \mathrm{~m}, \mathrm{~W}=0.022 \mathrm{~m}$ and $\mathrm{s}=0.001510^{-3} \mathrm{~m}$. After the calculation of the resistivity, conductivity can be easily obtained by (2):

$$
\sigma=\frac{1}{\rho}
$$

Where $\rho=$ resistivity $[\Omega \cdot \mathrm{m}]$, calculated from $(1), \sigma=$ conductivity $[\mathrm{S} / \mathrm{m}]$.

\section{Results and discussion}

\subsection{FT-IR Spectroscopy}

As mentioned, FT-IR, was used to assess the effectiveness and the degree of the reduction process. The IR spectra of all the membranes prepared are shown in Fig. 7.

In the spectrum of membrane prepared by GO solution it is possible to point out all the characteristic peaks of GO. In particular: at $3419 \mathrm{~cm}^{-1}$ stretching of hydroxyl groups is present; at $1730 \mathrm{~cm}^{-1}$ it is possible to find stretching vibration of carboxyl groups; stretching of $\mathrm{sp}^{2}$ carbon and bending of hydroxyl groups of water are both responsible of the peak at $1623 \mathrm{~cm}^{-1}$; at $1396 \mathrm{~cm}^{-1}$ there is the bonding vibration of hydroxyl bond; at $1235 \mathrm{~cm}^{-1}$ and $1064 \mathrm{~cm}^{-1}$ it is possible to find the stretching of epoxy group and of carboxyl group, respectively. All these peaks are aligned with other literature studies $[12,23,24]$.

Reporting in the same graph only r-GO $24 \mathrm{~h}, \mathrm{r}-\mathrm{GO} 48 \mathrm{~h}, \mathrm{r}-\mathrm{GO} 96 \mathrm{~h}$ spectrum, compared to $\mathrm{GO}$ spectra, it is possible to clearly define how the intensity of the peaks decreases as the time of reduction increases [18, 24] (Fig. 8 on the left). This is due to a lower presence of polar substituents on molecular structure of graphene GO. These groups are the cause of self - assembling properties of graphene oxide: on r-GO 96h spectra, where the reduction is pushed on, substituents peaks present very low intensity. It is possible to point out how in this membrane, $\mathrm{r}-\mathrm{GO} 96 \mathrm{~h}$, self-assembling properties are missing, as Fig. 4 has shown previously. 


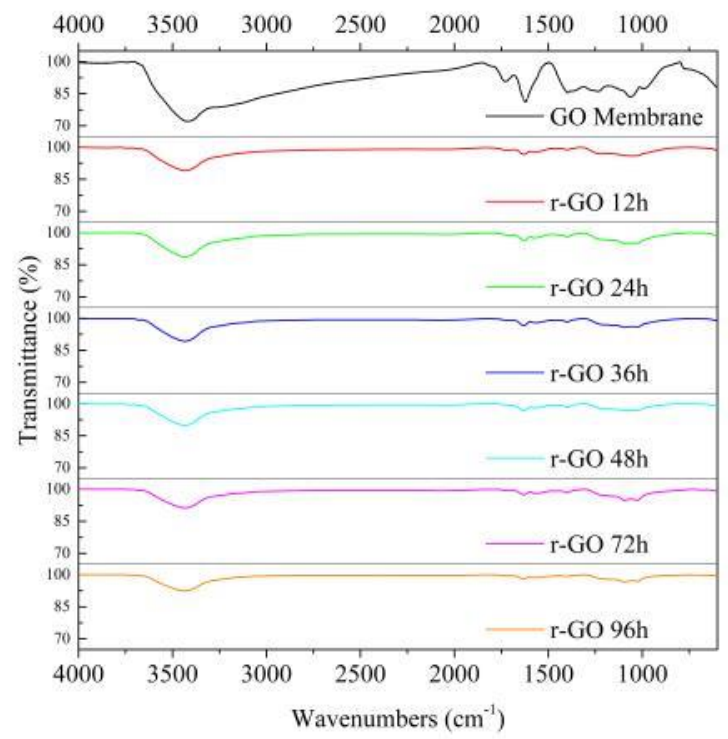

Fig. 7. Spectra of all samples.
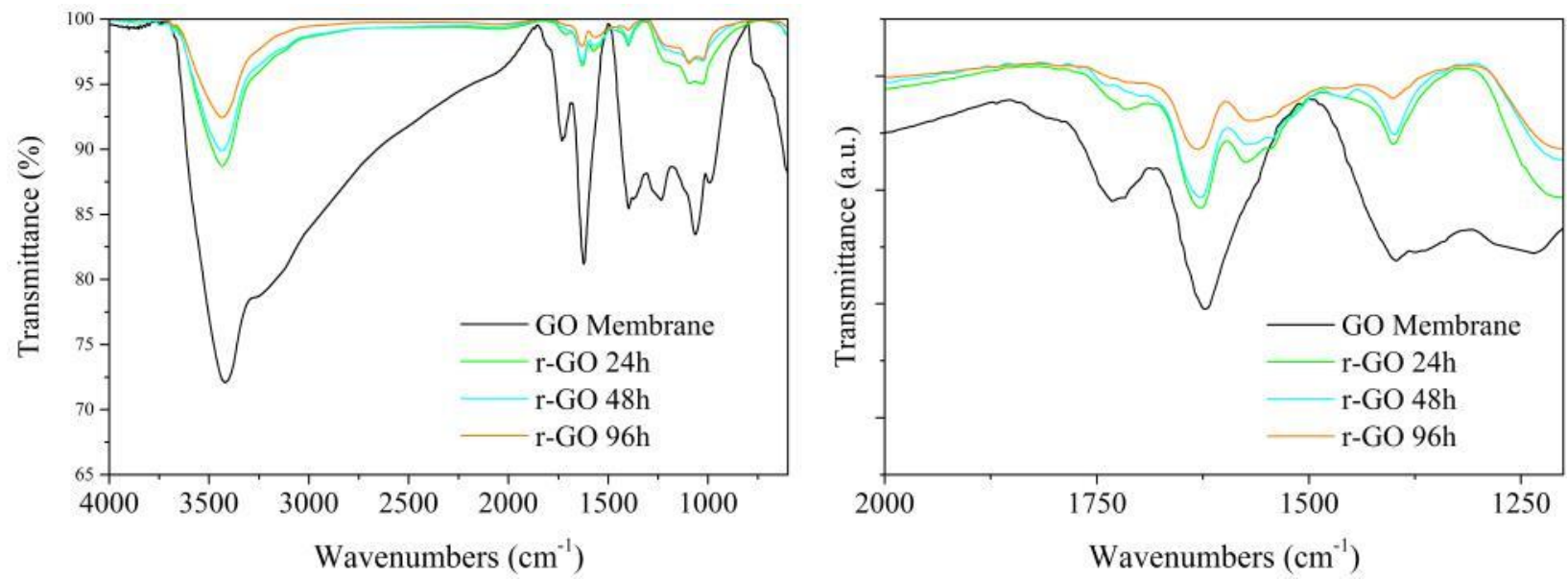

Fig. 8. Spectra of GO membrane, r-GO 24h, r-GO 48h, r-GO 96h. $4000-600 \mathrm{~cm}^{-1}$ (on the left); enlargement: zone $2000-1200 \mathrm{~cm}^{-1}$ (on the right).

Analyzing the zone in the range $2000-1200 \mathrm{~cm}^{-1}$, Fig. 8 on the right, it is possible to highlight several phenomena. It can be noted that peak at $1732 \mathrm{~cm}^{-1}$, corresponding to the stretching of carboxyl group $-\mathrm{COOH}$, decreases to flattening after $48 \mathrm{~h}$ of reduction.

It can be determined that the peak, related to the bending vibration of the hydroxyl group -OH present on water at $1600 \mathrm{~cm}^{-1}$, decreases in intensity and becomes less thick, while the peak of stretching vibration of $\mathrm{sp}^{2}$ carbon bond $-\mathrm{C}=\mathrm{C}$ - rises at $1570 \mathrm{~cm}^{-1}$ [25]. This indicates a lower amount of water in the membranes, due to lower amount of polar substituents in the GO molecule accessible to hydrogen bond with water, and so a low amount of intercalated water [26]. Moreover this rising peak represents a graphene structure. 


\subsection{Thermogravimetric analysis, $T G A$}

Another technique used to determine the amount of the residual polar substituent on GO molecule is thermogravimetric analysis. The weight losses as a function of temperature of all samples are represented in Fig. 9.

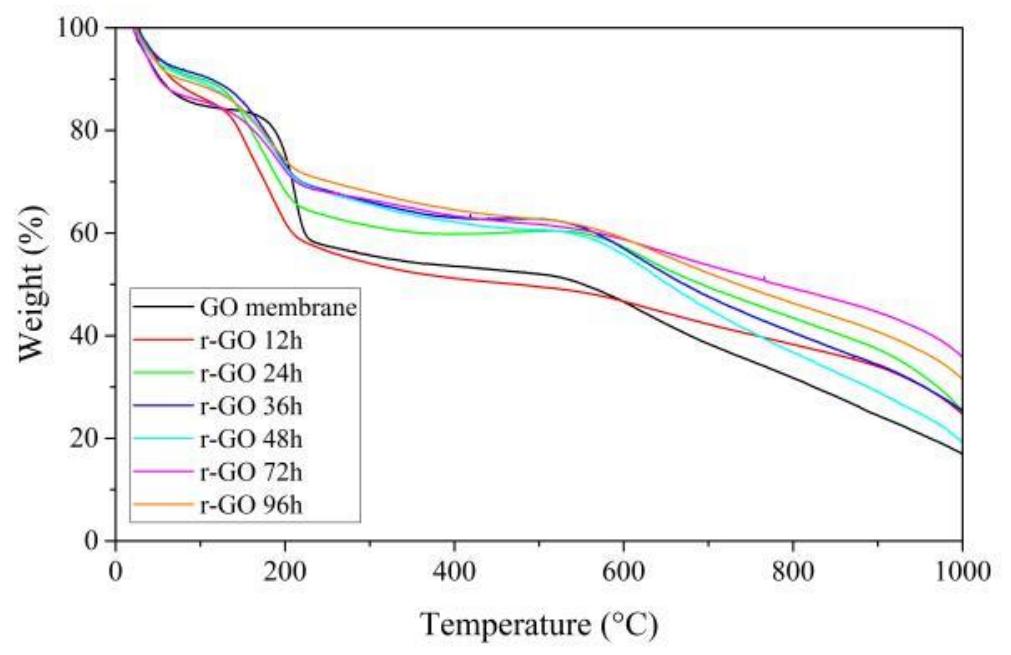

Fig. 9. Weight loss of all samples.

It is possible to note five different parts of the graphs, indicating different degradation process. In particular: first part (ca. $25-65^{\circ} \mathrm{C}$ ) is connected to the loss of water adsorbed on membrane due to humidity; second one (ca. 65 $135{ }^{\circ} \mathrm{C}$ ) should be attributed to intercalated water [27]; the third part [135-215 ${ }^{\circ} \mathrm{C}$ ], which is the main loss, is related to the loss of the weaker substituents from $\mathrm{GO} / \mathrm{r}-\mathrm{GO}$ molecules, that still remain after reduction of base solution $[12,28]$; in the temperature range between $215^{\circ} \mathrm{C}$ and $500{ }^{\circ} \mathrm{C}$, it is possible to correlate the weight loss due to oxygen substituents strongly bonded to the main carbon molecule that were not eliminated by the reduction process [12]; last losses $\left(500-1000{ }^{\circ} \mathrm{C}\right)$ should be related to the slow degradation of the carbon ring. It can be observed that for all the sample, both GO and r-GO based, residual is quite high [27].

Analyzing the third part corresponding to the decomposition of the weaker polar substituents bonded to the base molecule and plotting the values of weight loss, Fig. 10, it should be possible to extrapolate a decreasing trend, that is, in general, less substituents remain on GO structure as the reduction time increases. Values at low time of reduction of the base GO solution, such as $12 \mathrm{~h}$ and $24 \mathrm{~h}$, are higher than that obtained with GO specimen, maybe due to byproducts of reduction reaction, such as oxalic and guluronic acids $[15,18]$, that can intercalate, by hydrogen bond, and remain among r-GO platelets. This particular behavior has to be investigated by further and deeper analysis. 

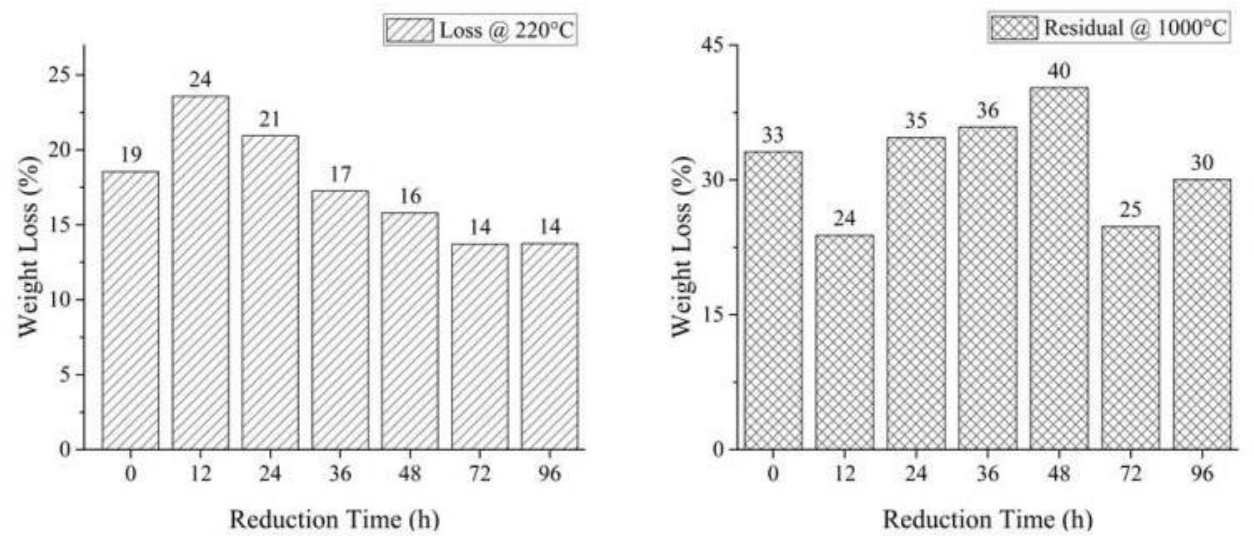

Fig. 10. Weight losses at $200{ }^{\circ} \mathrm{C}$ (on the left) and residual at $1000{ }^{\circ} \mathrm{C}$ (on the right) for all the samples. $0 \mathrm{~h}$ of reduction refers to GO membrane.

\subsection{Scanning electron microscopy, SEM}

To evaluate surface regularity and thickness of samples as a function of reduction of the base solution, surface and cross section SEM images were acquired. Henceforth, samples obtained for 72 and $96 \mathrm{~h}$ were excluded because they do not show self-assembling properties.

First surface images, collected at 5000X, are presented in Fig. 11.
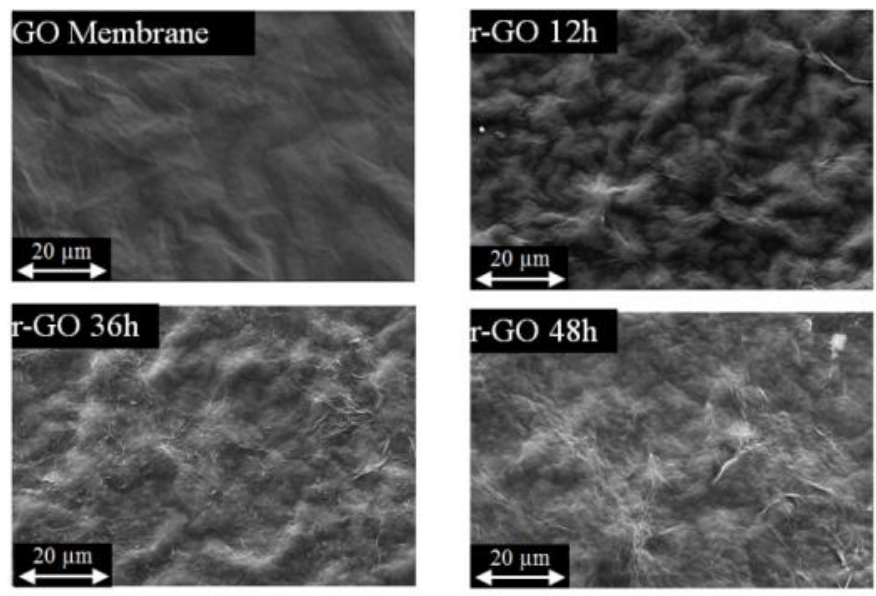

Fig. 11. SEM images of different samples at 5000X.

It is possible to see that GO membrane shows a smooth surface, without any non-planar irregularity, as reported in literature [21, 29]. As the reduction time increases, the surface irregularity increases and it seems that some platelets exit from the membrane plane.

Representative images of cross section are shown in the Fig. 12. 


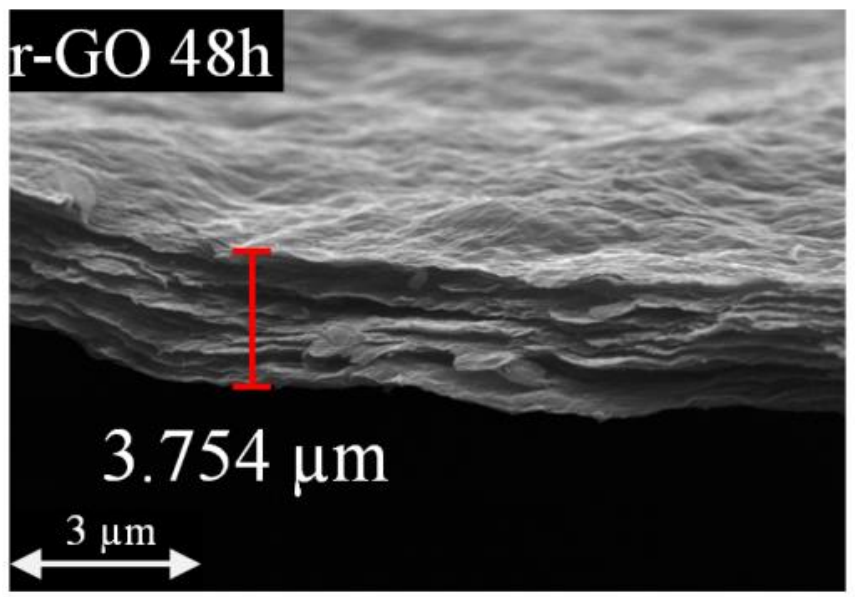

Fig. 12. Lateral image of r-GO $48 \mathrm{~h}$ at $5000 \mathrm{X}$..

It is possible to point out the multilayer structure due to the production process. From several values of thickness, measured during SEM analysis, Table 2, it is not possible to correlate thickness with reduction time. However, all the self-assembled membranes do not show any surface cracks, revealing a surface homogeneity despite of their small thickness.

Table 2. Different measures of membranes thickness.

\begin{tabular}{cccccccc} 
Sample & GO & r-GO 12h & r-GO 24h & r-GO 36h & r-GO 48h & r-GO 72h \\
\hline \multirow{2}{*}{ Thickness $[\mu \mathrm{m}]$} & 1.400 & 0.926 & 1.222 & 2.834 & 3.085 & 2.107 \\
& 0.789 & 2.470 & 1.853 & 0.796 & 1.407 & 0.945 \\
\hline
\end{tabular}

\subsection{X-Ray diffraction, XRD}

X-Ray diffraction was performed to assess the structural organization of specimen membranes. As mentioned, the analysis was taken with Millipore Membrane as substrate. XRD pattern of all tested samples and of Millipore membrane are reported in Fig. 13. 


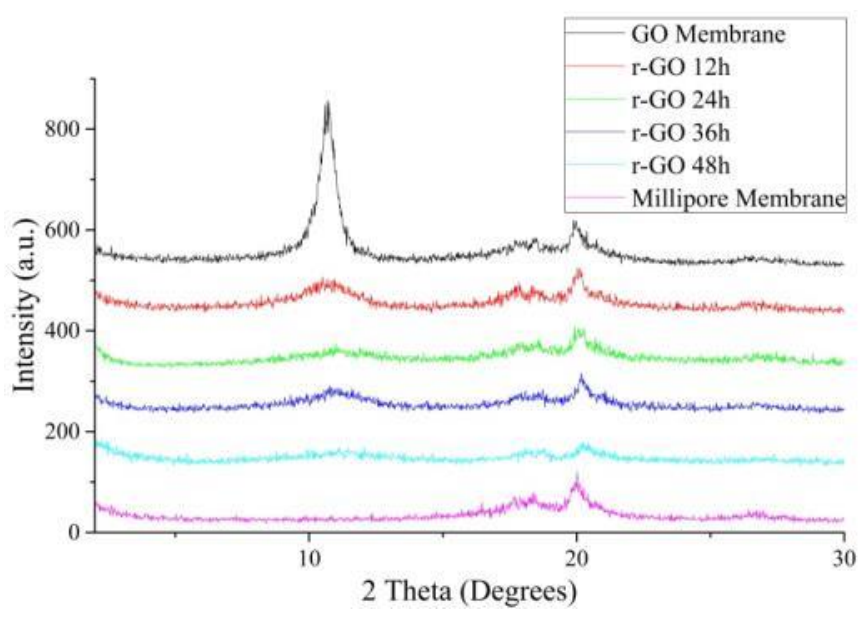

Fig. 13. XRD patterns of all tested samples.

In the pattern of GO membrane it is possible to define the characteristic peak of graphene oxide, around $2 \theta=$ $10.70^{\circ}$, corresponding to an interlayer distance of about $8 \AA$, and the contribution of Millipore Membrane, composed by two small peaks around $2 \theta=18^{\circ}$ and $2 \theta=20^{\circ}$. The interlayer distance of GO is two-fold the one of graphite, of about $3.4 \AA$, and it is due to intercalated water and oxygen functional groups that increase the d-spacing $[25,30]$.

It is possible to depict how the proper peak of graphene oxide decreases as the reduction time of the base solution is increased, due to an amorphization of the materials composing the membranes. Analyzing literature it is found another peak around $2 \theta=24^{\circ}$ rising during reduction of GO, which indicates the restore of graphitic structure [25, 30]. In samples analyzed in this study there is not any evidence of this. Further analysis are needed to explore this behavior. A possible explanation is that the ratio AA:GO 10:1 is probably too high and reduction excess byproducts, or unreacted AA, intercalate with remaining polar groups by hydrogen bond, thus disrupting the crystallinity of rising graphitic structure.

\subsection{Contact angle measurements, $C A$}

For PEMFC application it is essential to measure wettability of the material used to compose GDL. To assess hydrophobicity of samples, contact angle measurements were performed. Obtained data, with standard deviation, are shown in Fig. 14. 


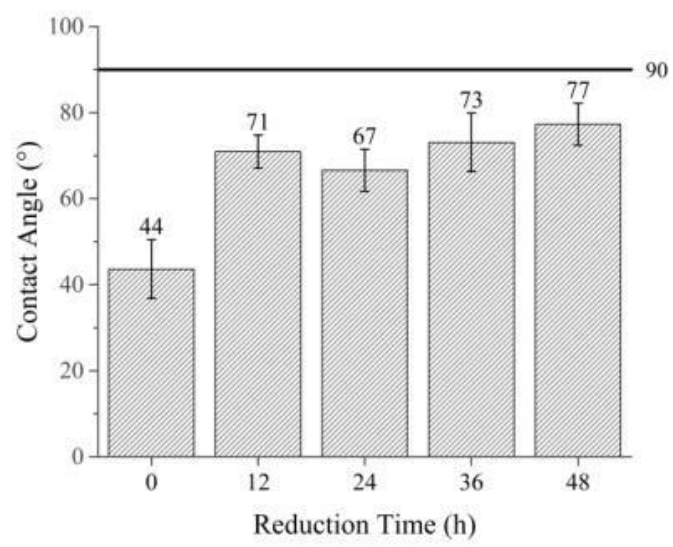

Fig. 14. Contact angle of all samples as function of reduction times of base solution. $0 \mathrm{~h}$ of reduction refers to GO membrane.

It is easy to predict that wettability decreases as the time of reduction of the base solution increases, due to lower amount of polar substituents into the graphene molecule after reduction. Contact angle rises of about $25^{\circ}-30^{\circ}$ passing from GO membrane to a r-GO membrane; this result is confirmed in literature, although upon a different reduction way [31]. However, for reduced membranes, it is possible to notice that CA values do not vary significantly, but only a slight increase is visible.

\subsection{Electrochemical impedance spectroscopy, EIS}

As final step, conductivity of sample membranes were calculated. As mentioned, this property is important to define a good GDL material. In this analysis only samples GO, r-GO 24h and r-Go 48h were tested.

In paragraph 2.3.1 the method to calculate conductivity, based on resistance measurements, has been explained. As an example, some impedance spectra of tested samples are reported in Fig. 15. These spectra allow to get resistance values which permit to calculate resistivity and so conductivity of the membranes. Values obtained are reported in Table 3 and calculated considering a thickness of $1.5 \mu \mathrm{m}$. 


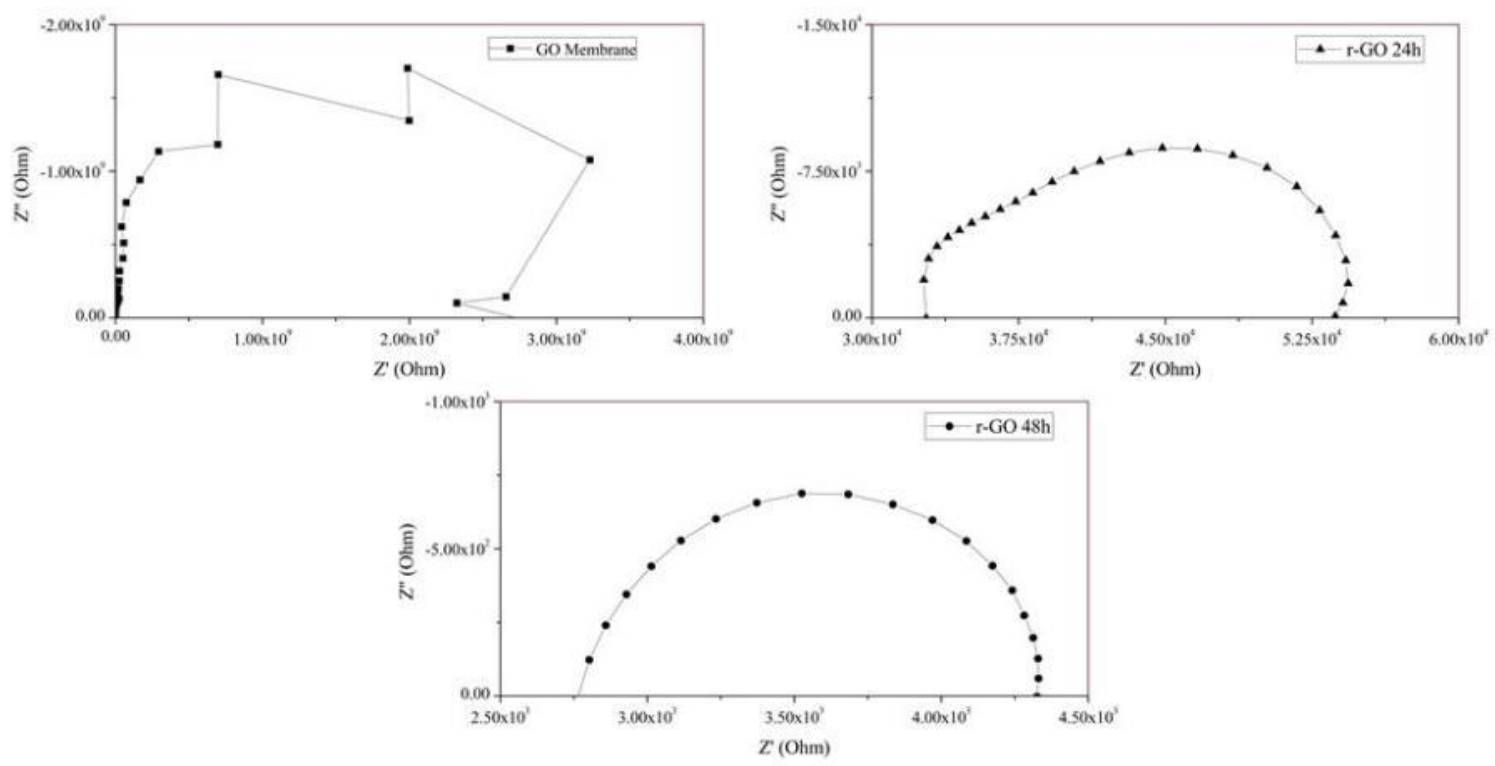

Fig. 15. Examples of obtained Nyquist diagrams of GO membrane, r-GO 24h, r-GO 48h.

Table 3. Resume of calculated conductivities.

\begin{tabular}{llll} 
Sample Membranes & $\begin{array}{l}\text { Resistance } \\
{[\Omega]}\end{array}$ & $\begin{array}{l}\text { Resistivity } \\
{[\Omega \cdot \mathrm{m}]}\end{array}$ & $\begin{array}{l}\text { Conductivity } \\
{[\mathrm{S} / \mathrm{m}]}\end{array}$ \\
\hline GO & $2.67 \times 10^{9}$ & $4.01 \times 10^{3}$ & $2.50 \times 10^{-4}$ \\
r-GO 24h & $2.23 \times 10^{4}$ & $3.32 \times 10^{-3}$ & $3.01 \times 10^{-1}$ \\
r-GO 48h & $1.58 \times 10^{3}$ & $2.23 \times 10^{-3}$ & $4.22 \times 10^{2}$ \\
\hline
\end{tabular}

Observing Table 3 it is possible to define that GO membrane shows typical value of an insulator. Conductivity increases upon increasing reduction time. This is due to graphene structure rising and to a lower amount of polar substituents present on r-GO platelets that compose samples and constitute some chemical-physical barrier to the charge movements..

\section{Conclusion}

The control of GO reduction is necessary to create a material that should be used as GDL in PEMFC application: r-GO demonstrates both hydrophobic and conduction properties, but at the same time shows a good self-assembling characteristic, composing membranes also after $48 \mathrm{~h}$ of reduction of the base GO solution.

The reduction method that was chosen for this study permits to have a control of the properties of the resulting reduced graphene oxide.

Membrane produced by filtration of GO solution reduced for $48 \mathrm{~h}$ gives best results concerning wettability and conductivity: a maximum CA of $86{ }^{\circ} \mathrm{C}$, that is near to be hydrophobic, and a conductivity of about $422 \mathrm{~S} / \mathrm{m}$. The obtained CA is an hopeful value but it needs to be improved: from literature it can be noticed that the hydrophobic properties of GDL are essential to have a good efficiency on PEM-FC, and GDL needs to have almost super- 
hydrophobic characteristics [2]. The obtained conductivity is a very good value: a commercial GDL, tested in the same conditions of membranes studied in this work, shows a conductivity of about $600 \mathrm{~S} / \mathrm{m}$.

From SEM analysis of cross section of the membranes it is pointed out that thickness is in the order of micrometers, with a maximum value of $4 \mu \mathrm{m}$. To avoid electric short circuit, give more mechanical toughness and uniform reagents flux in the PEMFC it will be mandatory to increase the thickness. In order to reach this goal the regulation of the vacuum in the membrane production step needs to be controlled.

Membranes presented in this work are still far from being used in a PEMFC. Reduced graphene oxide, as mentioned, permits to obtain conductive, homogeneous and self-assembled objects, in this case membranes. So reduced graphene oxide will be useful in composite material, such as compounds with carbon nanotubes, obtaining GDLs with enhanced properties that do not present cracks due to their production process [2].

\section{Acknowledgements}

This project was partially financed by Rold Research (www.roldresearch.org). All the industrial and technical partners of Rold Research are gratefully acknowledged.

\section{References}

[1] F. Barbir, PEM Fuel Cells (Second Edition), Academic Press, Boston, 2013

[2] S. Latorrata, P. Gallo Stampino, C. Cristiani and G. Dotelli, International Journal of Hydrogen Energy 40 (2015) 14596-14608

[3] S. Park, J.-W. Lee and B. N. Popov, International Journal of Hydrogen Energy 37 (2012) 5850-5865

[4] A. Jayakumar, S. P. Sethu, M. Ramos, J. Robertson and A. Al-Jumaily, Ionics 21 (2015) 1-18

[5] D. R. Dreyer, S. Park, C. W. Bielawski and R. S. Ruoff, Chemical Society Reviews 39 (2010) 228-240

[6] K. Krishnamoorthy, M. Veerapandian, K. Yun and S. J. Kim, Carbon 53 (2013) 38-49

[7] C. Chen, Q.-H. Yang, Y. Yang, W. Lv, Y. Wen, P.-X. Hou, M. Wang and H.-M. Cheng, Advanced Materials 21 (2009) $3007-3011$

[8] O. C. Compton and S. T. Nguyen, Small 6 (2010) 711-723

[9] J.-J. Shao, W. Lv and Q.-H. Yang, Advanced Materials 26 (2014) 5586-5612

[10] K. P. Loh, Q. Bao, G. Eda and M. Chhowalla, Nat Chem 2 (2010) 1015-1024

[11] S. Pei and H.-M. Cheng, Carbon 50 (2012) 3210-3228

[12] M. J. Fernández-Merino, L. Guardia, J. I. Paredes, S. Villar-Rodil, P. Solís-Fernández, A. Martínez-Alonso and J. M. D. Tascón, The Journal of Physical Chemistry C 114 (2010) 6426-6432

[13] S. Stankovich, D. A. Dikin, R. D. Piner, K. A. Kohlhaas, A. Kleinhammes, Y. Jia, Y. Wu, S. T. Nguyen and R. S. Ruoff, Carbon 45 (2007) $1558-1565$

[14] S. Park, J. An, J. R. Potts, A. Velamakanni, S. Murali and R. S. Ruoff, Carbon 49 (2011) 3019-3023

[15] S. Thakur and N. Karak, Carbon 94 (2015) 224-242

[16] C. K. Chua and M. Pumera, Chemical Society Reviews 43 (2014) 291-312

[17] A. Bagri, C. Mattevi, M. Acik, Y. J. Chabal, M. Chhowalla and V. B. Shenoy, Nature Chemistry 2 (2010) 581-587

[18] J. Zhang, H. Yang, G. Shen, P. Cheng, J. Zhang and S. Guo, Chemical Communications 46 (2010) 1112-1114

[19] C.-H. Tsou, Q.-F. An, S.-C. Lo, M. De Guzman, W.-S. Hung, C.-C. Hu, K.-R. Lee and J.-Y. Lai, Journal of Membrane Science 477 (2015) 93-100

[20] D. A. Dikin, S. Stankovich, E. J. Zimney, R. D. Piner, G. H. B. Dommett, G. Evmenenko, S. T. Nguyen and R. S. Ruoff, Nature 448 (2007) 457-460

[21] G. Liu, W. Jin and N. Xu, Chemical Society Reviews 44 (2015) 5016-5030

[22] H.-K. Jeong, Y. P. Lee, M. H. Jin, E. S. Kim, J. J. Bae and Y. H. Lee, Chemical Physics Letters 470 (2009) 255-258

[23] S.-b. Zhang, Y.-t. Yan, Y.-q. Huo, Y. Yang, J.-1. Feng and Y.-f. Chen, Materials Chemistry and Physics 148 (2014) 903-908

[24] C. Xu, X. Shi, A. Ji, L. Shi, C. Zhou and Y. Cui, PLoS ONE 10 (2015) e0144842

[25] V. Loryuenyong, K. Totepvimarn, P. Eimburanapravat, W. Boonchompoo and A. Buasri, Advances in Materials Science and Engineering 2013 (2013) 5

[26] M. Acik, C. Mattevi, C. Gong, G. Lee, K. Cho, M. Chhowalla and Y. J. Chabal, ACS Nano 4 (2010) 5861-5868

[27] B. Saswata and T. D. Lawrence, Nanotechnology 25 (2014) 075702

[28] H. A. Becerril, J. Mao, Z. Liu, R. M. Stoltenberg, Z. Bao and Y. Chen, ACS Nano 2 (2008) 463-470

[29] Y. Han, Z. Xu and C. Gao, Advanced Functional Materials 23 (2013) 3693-3700

[30] H. Sun, S. Liu, G. Zhou, H. M. Ang, M. O. Tadé and S. Wang, ACS Applied Materials \& Interfaces 4 (2012) 5466-5471

[31] F. Perrozzi, S. Croce, E. Treossi, V. Palermo, S. Santucci, G. Fioravanti and L. Ottaviano, Carbon 77 (2014) 473-480 